\title{
Performance at a Precognitive Remote Viewing Task, with and without Ganzfeld Stimulation: Three Experiments ${ }^{1}$
}

\author{
Chris A. Roe, Callum E. Cooper, Laura Hickinbotham, \\ Andrew Hodrien, Laurrie Kirkwood, and Hannah Martin \\ University of Northampton
}

\begin{abstract}
Recent research by the lead author has sought to incorporate ganzfeld stimulation as part of a remote viewing protocol. An initial exploratory experiment (Roe \& Flint, 2007) suggested that novice participants can successfully describe a randomly selected target location while in the ganzfeld context but did not make a direct comparison with performance in a waking state. This paper describes a series of three subsequent experiments that compared performance at a remote viewing task in a waking condition with a ganzfeld stimulation condition using a counterbalanced repeated measures design. There were only minor variations in design across the three experiments to enable combination of data in a summary analysis. In total, 110 participants produced 43 hits in the ganzfeld stimulation condition (39\%), giving a highly significant positive deviation from chance expectation (sum of ranks $=225, p=.000012)$, whereas in the waking RV condition they achieved 30 hits (27.5\%), which is marginally better than chance expectation (sum of ranks $=253, p=.034$ ). The difference in $z$ scores for target ratings in the two conditions approached significance $(t[39]=1.86, p=.065)$. In experiment 1 , individual difference measures identified as predictors of psi performance were unrelated to target ratings. Participants completed Pekala's (1991) Phenomenology of Consciousness Inventory $(\mathrm{PCl})$ in order to gauge their responsiveness to the ganzfeld protocol and of the 12 sub-dimensions tested, ganzfeld performance correlated significantly with greater absorption in their subjective experience, lower arousal, and less internal dialogue. In experiments 2 and 3 individual differences measure were replaced by measures of transliminality, openness to experience, and dissociative experiences, but these were unrelated to task success. Data from experiment 2 did not confirm the findings using the $\mathrm{PCl}$ from experiment 1, though a significant association was found with the time sense dimension. In experiment 3 no $\mathrm{PCl}$ dimensions correlated with task performance, a pattern that was confirmed when data were combined across all three experiments.
\end{abstract}

Remote viewing (RV) can be defined as "the ability to perceive and to be able to describe what would be experienced if one were at some specified distant location" (after Hansel, 1989, p. 160). Al-

1 We should like to thank the Perrott-Warrick Fund, the Society for Psychical Research Research Grants Committee and the Parapsychological Association Research Endowment (PARE) Fund for their kind financial support of the experiments included in this series. Address correspondence to: Prof. Chris Roe, Faculty of Health, Education \& Society, The University of Northampton, University Drive, , Northampton NN1 5PH, UK. 
though the method can vary in practice (cf. Schwartz, 2015; Utts \& May, 2003), experimental work typically involves a protocol in which the sender visits a randomly selected remote location and actively engages with the target material by attending to the features of the site and participating in activities appropriate to it (see Targ, 1994, for a more detailed description). Meanwhile, the receiver is led through a series of visualization techniques while in an ordinary waking state of consciousness by an experimenter who, masked to the identity of the target, directs them to describe particular features of the site using an interview format (Baptista, Derakshani, \& Tressoldi, 2015).

From its inception at SRI as a means of testing for ESP with Ingo Swann and its first published formal testing with Pat Price (Targ \& Puthoff, 1974, 2005), the method seems to have been remarkably successful; so much so that when Utts (1996) was asked to review the evidence accumulated under the SRI and SAIC programs, she asserted: "Using the standards applied to any other area of science it is concluded that psychic functioning has been well established" (p. 3). Some of the early work at SRI has been criticized (Marks \& Kamman, 1980), particularly with respect to potential problems with the randomization and editing of transcripts, which might have left cues to the order in which sites served as targets. These concerns were challenged by Tart, Puthoff, and Targ (1980), who demonstrated that when cues were removed a new independent judge was still able to match transcripts to target sites to a highly significant degree. Later, successful replications (e.g., Schlitz \& Gruber, 1980, 1981; Schlitz \& Haight, 1984), similarly took great care to ensure that neither the order of target selection nor of the transcripts could be inferred from material they contained. However, part of that solution involves either editing the transcripts, which itself can be grounds for criticism (e.g., Marks \& Kamman, 1980, p. 16), or deferring feedback about target identities until the end of the series, which may be de-motivating (see, e.g., Tart, 2007). Of course, these concerns only apply to studies in which the same participant serves as viewer for a number of trials in the series, and thus is potentially able to refer in their transcripts to earlier targets and later planned sessions - this would not be possible if one were to adopt a design in which a larger number of participants contributed just one trial each.

Militating against the use of a larger sample of participants is the difficulty in finding a sufficient number of able persons; for example, Utts (1996) estimated that only around $1 \%$ of those screened were suitable for RV work. This might be overcome if an induction procedure could be identified that facilitated the performance of novice participants. One candidate is the ganzfeld induction procedure. Although the ganzfeld does not necessarily induce a hypnagogic state (Wackermann et al., 2002), it does seem to share properties with other psi-conducive states that distinguish it from a "standard" RV protocol, such as systematically reducing external sensory stimulation and passively shifting the participants' attention to internal sources of information (Braud \& Braud, 1973; Honorton, 1977; Parker, 1975). There is some evidence to suggest that novice participants may be able to succeed at a free response ESP task under laboratory conditions where it incorporates a ganzfeld-induced altered state of consciousness (ASC; e.g., Baptista et al., 2015; Storm et al., 2010).²

The lead author conducted a pilot study (Roe \& Flint, 2007) to test the speculation that ganzfeld stimulation might enable novice participants to succeed at a remote viewing task. Fourteen sender-receiver pairs of novice participants each contributed one remote viewing trial. Receivers underwent a

2 This is not to say that unselected participants are necessarily able to perform at similar levels as selected participants, but rather to note that unselected participants may be able to perform above chance expectation when conditions are conducive. 
progressive relaxation induction procedure followed by ganzfeld stimulation, during which they reported their sensory experiences, with the intention of describing a randomly-selected target site to which their sender partner had been sent. On completion of the trial the sender returned to provide feedback about the nature of the target. An independent judge ranked all 8 possible locations against each mentation, producing 12 binary hits across the 14 trials and a combined sum of ranks that was significant $(S O R=42, p=.008)$, suggesting that this approach might overcome the weaknesses just outlined.

Although the study was successful, it was not clear whether this was a consequence of incorporating a ganzfeld protocol for our novice participants, since we did not have a comparison condition in which those participants attempted to generate impressions about a target location without the assistance of ganzfeld stimulation. The current experimental series was designed to address this shortcoming.

Recruiting a wide range of participants allows researchers to explore various individual differences factors (such as personality, belief, and prior experiences) to determine whether they are associated with task success. Given that extant remote viewing research had paid relatively little attention to individual differences, we took our lead from other free response literature. We speculated (after Honorton, 1997; Roe, Jones \& Maddern, 2007) that performance might be related to practice of a mental discipline, personal psi experience, paranormal belief, Feeling-Perceiving personality type as measured by the Myers-Briggs Type Indicator, extraversion, and self-rated creativity (see Cardeña \& Marcusson-Clavertz, 2015, for a more thorough review of individual differences variables associated with psi).

Additionally, working with a range of participants allows us to consider individual differences in responsiveness to ganzfeld stimulation. The lead author has been a vocal advocate (e.g., Roe, 2009) of Stanford's criticism of ganzfeld researchers for implicitly assuming that this induction procedure elicits a uniform response from all participants. In practice it is clear that some participants experience no shift at all from their ordinary waking state so that they will not benefit from any psi-conducive properties it supposedly confers. We therefore planned to investigate whether subjective shifts in state of consciousness, as measured using Pekala's (1991) Phenomenology of Consciousness Inventory (PCl) were associated with better performance at the remote viewing task.

Finally, it is difficult with a telepathy design to unequivocally rule out collusion between sender and receiver; the sound attenuated laboratory available to us at the University of Northampton does not have electromagnetic shielding so that a participant who is determined to cheat could conceivably bring a hidden device with them. Although an experimenter remains with the receiver during the session so that normal communication would be impossible, more subtle signals (for example based on silent vibration of calls) could go undetected. These hypothetical concerns can be readily addressed by adopting a precognitive design in which the target has not yet been randomly selected at the time that the mentation is generated.

We therefore pre-specified the following hypotheses:

$\mathrm{H}_{1}$ : Performance in the ganzfeld condition will be better than mean chance expectation (MCE) as measured by sum of ranks analysis of the independent judge's ranking of the target ${ }^{3}$

3 In free response ESP experiments at the University of Northampton, sum of ranks has always been our primary outcome measure in preference to direct hits analysis (e.g,. Roe et al., 2003; Roe et al., 2007; Roe et al., 2004). 
$\mathrm{H}_{2}$ : Performance in the waking remote viewing condition will be better than MCE as measured by sum of ranks analysis of the independent judge's ranking of the target

$\mathrm{H}_{3 \mathrm{a}}$ : Participants who practice a mental discipline will perform better than those who do not, as measured by z-scores of the independent judge's similarity ratings for the target site in the ganzfeld condition. ${ }^{4}$

$\mathrm{H}_{3 \mathrm{~b}}$ : Participants who practice a mental discipline will perform better than those who do not, as measured by z-scores of the independent judge's similarity ratings for the target site in the waking remote viewing condition.

$\mathrm{H}_{4 \mathrm{a}}$ : Participants who report personal psi experiences will perform better than those who do not, as measured by z-scores of the independent judge's similarity ratings for the target site in the ganzfeld condition.

$\mathrm{H}_{4 b}$ : Participants who report personal psi experiences will perform better than those who do not, as measured by z-scores of the independent judge's similarity ratings for the target site in the waking remote viewing condition.

$\mathrm{H}_{5 a}$ : Participants who report belief in psi will perform better than those who do not, as measured by z-scores of the independent judge's similarity ratings for the target site in the ganzfeld condition.

$\mathrm{H}_{5 \mathrm{~b}}$ : Participants who report belief in psi will perform better than those who do not, as measured by z-scores of the independent judge's similarity ratings for the target site in the waking remote viewing condition.

$\mathrm{H}_{6 a}$ : Participants who are categorized as Feeling-Perceiving types on the Myers-Briggs Type Indicator will perform better than those who do not, as measured by z-scores of the independent judge's similarity ratings for the target site in the ganzfeld condition.

$\mathrm{H}_{6 b}$ : Participants who are categorized as Feeling-Perceiving types on the Myers-Briggs Type Indicator will perform significantly better than those who do not, as measured by z-scores of the independent judge's similarity ratings for the target site in the waking remote viewing condition.

$\mathrm{H}_{7 \mathrm{a}}$ : Participants who are categorized as Extraverts on the Myers-Briggs Type Indicator will perform better than those who do not, as measured by z-scores of the independent judge's similarity ratings for the target site in the ganzfeld condition.

$\mathrm{H}_{7 \mathrm{~b}}$ : Participants who are categorized as Extraverts on the Myers-Briggs Type Indicator will perform better than those who do not, as measured by z-scores of the independent judge's similarity ratings for the target site in the waking remote viewing condition.

4 Z-scores can be calculated by subtracting the target similarity rating from the mean of all ratings (target and decoys) and dividing this by the standard deviation for all ratings (cf. Palmer, 1986). Although a number of these hypotheses are directional, all analyses were conservatively set as 2-tailed. 
$\mathrm{H}_{8 \mathrm{a}}$ : Participants who identify as creative will perform better than those who do not, as measured by z-scores of the independent judge's similarity ratings for the target site in the ganzfeld condition.

$\mathrm{H}_{8 \mathrm{~b}}$ : Participants who identify as creative will perform better than those who do not, as measured by z-scores of the independent judge's similarity ratings for the target site in the waking remote viewing condition.

\section{Method: Experiment $1^{5}$}

\section{Design}

This study adopted a related design to compare precognition performance in ganzfeld stimulation and waking remote viewing conditions using a counterbalanced design. The primary outcome measure was pre-specified to be sum of ranks allocated to target sites by an independent judge. Further analyses were planned that would look for associations between scores on individual differences measures and z-scores of target similarity ratings.

\section{Participants}

Two research assistants (CC and HM) were appointed to work on this project. Although no formal measures were taken, all co-researchers in the three experiments reported here had taken an optional third year module in Parapsychology and the Psychology of Anomalous Experience and had contacted the principal author to express a desire to be more actively involved in research. All were at least open to the possibility of psi being demonstrated in their experiment. A convenience sample of 40 volunteers participated (28F, 12M; mean age $=26.2$, range $=18-54$ years), consisting of friends, family, and other students. Participants were not selected on the basis of prior belief or experience.

\section{Materials}

A participant information form (PIF) comprised standard briefing instructions and questions concerning biographical and contact details (6-items); belief in PK (3-items); previous participation in parapsychological studies (2-items); practice of mental/physical disciplines (1-item); creativity (2-items); and self-perceived happiness (1-item). Participants also completed the Keirsey Temperament Sorter (Keirsey \& Bates, 1978) - a variant of the Myers Briggs Type Indicator. The MBTI is a commonly used measure in clinical and consulting psychology and is adopted here because it has proven popular with ganzfeld researchers, although psychometric assessments have cast doubt on its reliability and validity (e.g., Boyle, 1995; Pittenger, 2005).

To measure shifts in state during ganzfeld stimulation, participants completed Pekala's (1991) Phenomenology of Consciousness Inventory, Form 1. At 53 items, the full scale was considered too long for current purposes so the two highest loading items from each of the following subscales were retained as the most relevant dimensions given the claimed effects upon subjective experience of ganzfeld stimulation: body image; time sense; direction of attention; absorption; imagery amount;

5 An account of this study was given by Roe et al. (2010). 
imagery vividness; self-awareness; altered state of awareness; arousal; rationality; volitional control; and internal dialogue.

Two pools of 20 target locations were identified to reflect a wide range of geographical features (see the Appendix for a full list). Each pool consisted of five sets, each containing four sites that were intended to incorporate distinct elements (e.g., a desert area versus a waterfall), so that they could be easily discriminable for the independent judge when rating against mentations. Two pools were used so that participants could not have the same location selected as the target for both trials while ensuring that they could not improve their performance on the second trial by simply avoiding elements of their first target site (i.e., both pools had waterfalls, deserts, city scenes, etc.). Targets were accessed using Google Earth so as to allow participants an opportunity to interact with the site, virtually travelling around it and viewing from different perspectives as well as opening photographs that had been taken there (see Figure 1).

\section{Procedure}

The project received approval from the Faculty Research Ethics Panel. This entailed providing a full description of what participation involved and of how data would be anonymized. Participants were reminded that they were free to withdraw at any time during the experiment without having to give a reason. All participants completed a consent form before data collection commenced.

Participants were recruited individually and completed the PIF before attending the laboratory to complete their trials. On arrival they were met by the participant's experimenter (PE), introduced to the two tasks, and given an opportunity to ask questions or discuss their own personal experiences that might have motivated their participation. Participants completed both a remote viewing and a ganzfeld condition with the order of completion counterbalanced across trials. Both trials took place in a sound attenuated laboratory.

In the ganzfeld condition the participants made themselves comfortable in a reclining armchair, PE placed eye shields over their eyes and fitted headphones over which white noise would be played. A standard desk lamp with a $40 \mathrm{~W}$ red light was shone in the face of the receiver from a distance of approximately $1 \mathrm{~m}$, giving a warm and relatively uniform visual field. Progressive relaxation instructions involving tensing and releasing muscles in different parts of the body and noticing the difference (after Dalton, 1997) were played in order to enable the participant to relieve muscular tension. Toward the end of the relaxation instructions, the participant instructions advised as follows:

You are now in a very relaxed, peaceful state. While you are in this relaxed state you find that from time to time you will experience images, sounds and bodily sensations. This is perfectly natural, as your unconscious produces its own imagery when there isn't much outside stimulation, much like a daydream or when drifting off to sleep. Just like drifting off to sleep, don't try and force this process, just relax and let things happen naturally - the images will appear at the appropriate time, and they will be related to the target location that you will get to visit later. When the impressions do occur, think out loud. Report all the distinctive images, thoughts and feelings you have as they occur, and continue to share them throughout the session. 
PE remained with the participant in the sound attenuated laboratory during the ganzfeld period and made a record of the ongoing commentary using a ganzfeld mentation sheet. The relaxation induction lasted about 7 minutes and the exposure to ganzfeld $30 \mathrm{~min}$. Towards the end of the session the Target Experimenter (TE) randomly selected a target location for that trial using the randomization function in Excel to choose a target set and a target location from within that set. TE had no contact with the participant.

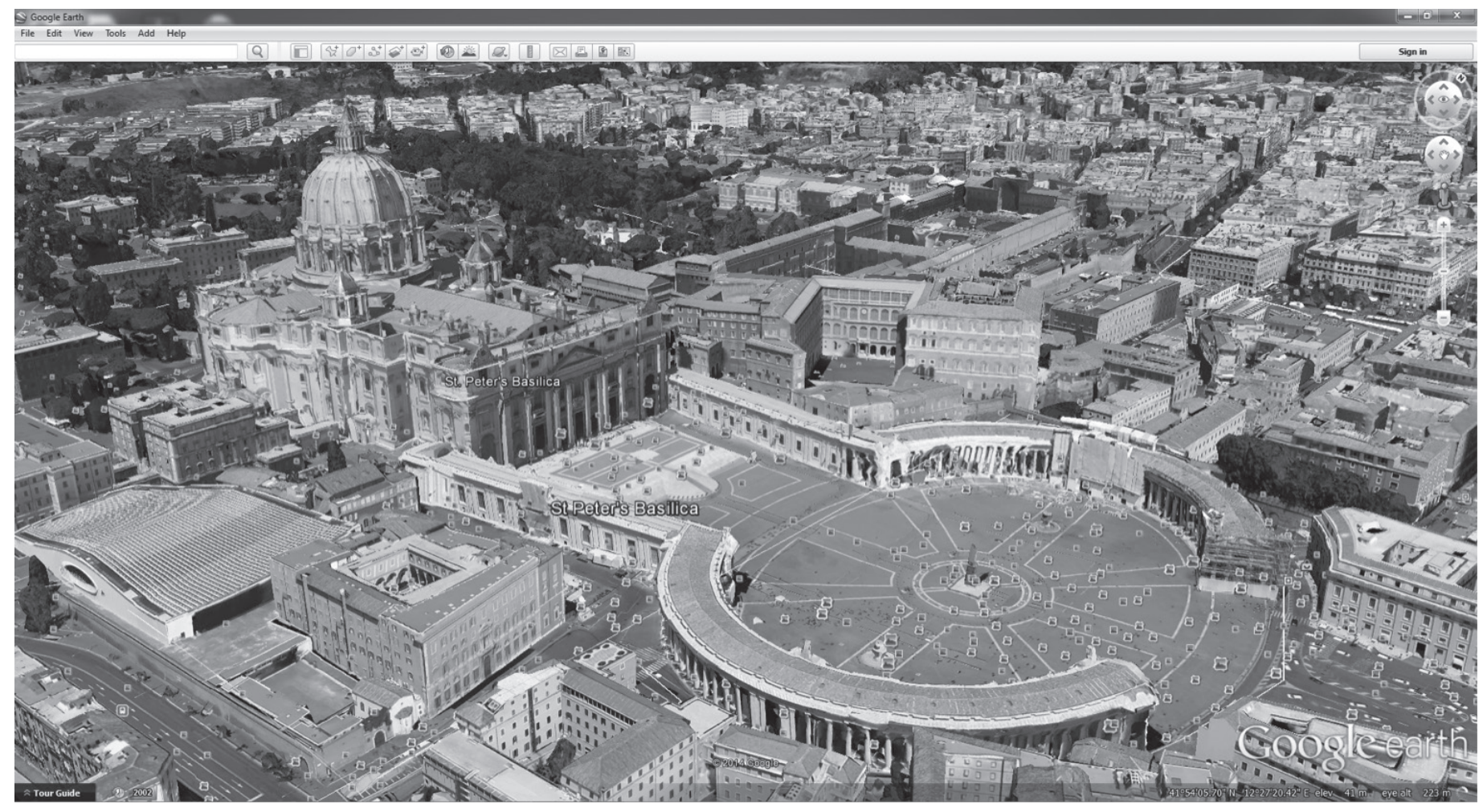

Figure 1. Example target location presented using Google Earth

Once the session was over, PE reviewed the mentation with the participants and gave them the opportunity to add to it or correct any errors. The participant was then given the abridged $\mathrm{PCl}$ to complete while PE took the mentation sheet to TE and together they made a copy of the record sheet, with the original being filed away and the copy used during participant feedback. Once the mentation had been photocopied, TE would inform PE of the target identity and the participant would view the location in the sound attenuated laboratory with PE, who remained with them and encouraged them to look for correspondences between their mentation and the target site, even where these were relatively tenuous. Care was taken to ensure that participants spent some time engaging with their intended precognitive target.

For the remote viewing condition, participants returned to the sound attenuated laboratory and sat in the armchair in the upright condition and with lighting at normal levels. They were given the following instructions (adapted from Subbotsky \& Ryan, 2009):

Thank you for agreeing to participate in this remote viewing experiment. Remote viewing is a technique that helps you form a mental image of a distant location. The remote viewing procedure that you will be using was developed during a highly successful 20-year research 
program sponsored by the US government, and we are looking to see if it can be used successfully with ordinary members of the public.

In this experiment you will be asked to remote view a location that you will be shown at the end of the session. You will register your impressions about the target site by listing words that describe features of it and by drawing sketches. You will later be able to compare these against the actual location to look for possible correspondences, and afterwards an independent judge will give her own ratings.

Before you start your task, I will talk you through an exercise to clear your mind of clutter and background mental noise that might get in the way of any impressions about the target. Your experimenter will give you a blank sheet of paper and I would like you to jot down anything that might be on your mind. This could be everyday concerns, such as worries about an exam that's coming up, or anxiety about a row that you had with a friend recently, or worries about taking part in this experiment and doing well for the researcher. Be as honest as you can in writing down your concerns - no-one but you will see what you have written. Once you have written them down, we want you to crumple up your piece of paper into a ball and set aside those worries for now. At the end of the experiment you can take the sheet of paper away with you or you may decide to throw it away in the bin. The experimenter will stop this recording now and restart it after the mind clearing exercise.

Thank you for completing the mind clearing exercise. I will now tell you about the target location that you will remote view. The location will be an outdoor scene and can be anywhere in the world. It can be somewhere you have never heard of, so don't worry about trying to recognize or name it - we just want you to describe its features.

Remote viewing is a natural process like normal perception, but ordinarily when we describe our perceptions we tend to internally edit things before we speak. For example, if you have cats and you see a movement out of the corner of your eye then you will tend to label that experience as your cat walking by, when in fact all you experienced was a particular color and a particular movement. When we interpret an experience rather than just describe it, that's when mistakes can creep in. Likewise, in remote viewing this kind of editing or interpreting often leads to misinterpretation, so it important to stick with your first impressions without analyzing them too much. To help you do that, we will be asking you to describe basic features such as colors, tastes and smells, rather than asking you for very detailed or specific images. This procedure is a bit like a word association task in psychology where you might be asked to respond without thinking with the first word that pops into your head after hearing a stimulus word.

To begin, in the top right of your record sheet you should write the date, time and a signifier. This is a name, word or number that has some personal meaning for you and which symbolically connects you to the session without compromising your anonymity. Your experimenter will not ask you what your signifier means. You could use someone's initials, a favorite pet's 
name, a special date, or whatever you want. When you have done this you will be asked to put your pen on the paper at the top left of the record sheet. Your experimenter will then read out the coordinates for the target. You should write this number down and repeat the coordinate out loud to ensure that you have it correctly. As soon as you complete the coordinate you should immediately and without thinking about it produce a very brief sketch or scribble. This will be your connection with the target location. You should then describe the squiggle in terms of its basic features, such as whether the line goes up or down, whether it curves or changes direction abruptly, producing angles. You can also describe any immediate associations it suggests to you.

When you are ready you can move on to the next stage which is to describe your impressions of the target in terms of the different senses: colors, sounds, textures, tastes, smells, and so on. Keep in mind that different parts of the target might have different qualities, so don't worry if some of your descriptors seem contradictory. It can sometimes be useful to touch different parts of your sketch with your pen when you are trying to get impressions of different parts of the location. If you find that you don't have any further impressions you can ask your experimenter to give you the coordinates again and you can repeat the process of writing this number down and immediately scribbling a sketch that represents some aspect of the target.

When you feel you have enough descriptors, you can go on to draw freehand sketches that help you arrange those descriptors in space - which elements seem to go together and which seem to be quite separate. Please produce as many drawings as you like - your experimenter has lots of extra sheets of paper that you can use.

When you have completed the drawings, you should summarize your impressions by giving a short written description at the end of the record sheet.

The experimenter will now answer any questions you may have and then the remote viewing session will begin. Thanks again for taking part.

Following this introduction, participants first noted the session date and location, and then recorded the target site's co-ordinates as they were read out by PE. These co-ordinates were arbitrary (but unique) numbers rather than actual geographical co-ordinates. ${ }^{6}$ As soon as the co-ordinates were recorded the participant produced a quick freehand doodle denoted as the ideogram. Thereafter they provided a description of aspects of the designated site in terms of single-word adjectives that related to different sensory modalities (e.g. "blue", "cold", "grainy", "fresh", etc.). Participants were encouraged by PE to switch often between modalities (e.g. from visual to tactile descriptors). Once this list was exhausted the participant attempted to combine these descriptors into some kind of arrangement by drawing as many freehand sketches as they required. When participants felt that they had completed sufficient sketches, they provided a written summary of the site. Once the session was over, PE again gave them the opportunity to add to the account or correct any errors. PE again took the mentation sheet to TE and the procedure was similar to that for the ganzfeld session. The order of conditions was counterbalanced across participants.

6 Using actual co-ordinates leaves open the possibility that a participant may be exploiting savant-like capacities to memorize map co-ordinates. Targ and Puthoff (1977) found in their work with Ingo Swann that arbitrary number strings were just as effective. 
Record sheets were sent to an independent judge who was informed of the pool and set to which the target site belonged. ${ }^{7}$ She ranked all four locations in the set in terms of their applicability to the participant's description and gave each a similarity rating on a scale from 0 (no correspondence) to 99 (exact correspondence). Given the different methods for recording target descriptions, the independent judge was not masked as to the condition each trial belonged to.

\section{Results: Experiment 1}

Data from the experiments described in this paper are available through the Psi Open Data repository (https://open-data.spr.ac.uk/search/type/dataset). The ranks given to the actual target location on each of the 40 trials are given in Table 1. In terms of first place ranks for targets, the direct hit rate for the ganzfeld condition is 35\% (binomial $p=.10$ ) and for the remote viewing condition is 30\% (binomial $p=.29$ ), so that although both hit rates approximate values reported in previous studies they do not deviate significantly from MCE of $25 \%$. The primary outcome measure was pre-specified to be sum of ranks; by this measure, performance in the ganzfeld condition was significantly better than chance $(z=$ $1.77, p=.038)$; performance in the remote viewing condition was suggestively better than chance $(z=$ $1.63, p=.052)$ but was not significant. ${ }^{8}$

Z-scores were calculated using the independent judge's similarity ratings for target locations compared with ratings for decoys so as to look for co-variation in performance across participants that might be associated with personality and individual difference measures. We speculated that performance might be related to practice of a mental discipline, personal psi experience, more general paranormal belief, FP personality type, extraversion, and self-rated creativity. We can see from Table 2 that none of the predicted differences occurred; indeed, slightly better performance in the ganzfeld was achieved by those who did not practice a mental discipline, were not FP types, and rated themselves as less creative.

Table 1.

Sum of ranks for target locations for ganzfeld and remote viewing trials

\begin{tabular}{|c|c|c|c|c|c|c|c|c|}
\hline & \multicolumn{4}{|c|}{ Rank } & \multicolumn{2}{|c|}{ Sum of Ranks z-score } & \multirow[t]{2}{*}{$p$} & \multirow[t]{2}{*}{$E S^{11}$} \\
\hline & 1 & 2 & 3 & 4 & & & & \\
\hline Ganzfeld trials & $\begin{array}{c}14 \\
(35 \%)\end{array}$ & $\begin{array}{c}10 \\
(25 \%)\end{array}$ & $\begin{array}{c}11 \\
(28.5 \%)^{12}\end{array}$ & $\begin{array}{c}5 \\
(12.5 \%)\end{array}$ & 87 & 1.77 & .038 & .28 \\
\hline Waking RV trials & $\begin{array}{c}12 \\
(30 \%)\end{array}$ & $\begin{array}{c}16 \\
(40 \%)\end{array}$ & $\begin{array}{c}4 \\
(10 \%)\end{array}$ & $\begin{array}{c}8 \\
(20 \%)\end{array}$ & 88 & 1.63 & .052 & .26 \\
\hline
\end{tabular}

7 We should like to thank Jacqui Wilson for her assistance as the independent judge.

$8 \mathrm{We}$ are aware that it is imprudent to make dichotomous decisions based solely on a p value. The primary aim of this suite of experiments was to explore whether effects could be replicated and to produce effect size estimates based on cumulative data.

9 ES was calculated using $\mathrm{z} / \mathrm{sqrt}(\mathrm{n})$.

10 All percentages are rounded to the closest .5 . 
Table 2.

Mean z-scores and independent t-test statistics for trial outcome categorized by individual differences measures

\begin{tabular}{|c|c|c|c|c|c|c|}
\hline & & \multicolumn{2}{|c|}{ Mean z scores } & \multirow{3}{*}{$\begin{array}{c}t \\
\\
.52\end{array}$} & \multirow{3}{*}{$\begin{array}{c}p \\
\\
.61\end{array}$} & \multirow{3}{*}{$\begin{array}{c}\mathrm{ES}(r) \\
.08\end{array}$} \\
\hline & & Yes & No & & & \\
\hline \multirow{2}{*}{$\begin{array}{l}\text { Practice of a mental } \\
\text { discipline? }\end{array}$} & Ganzfeld & .17 & .32 & & & \\
\hline & Waking RV & .33 & .06 & -.93 & .36 & .15 \\
\hline \multirow{2}{*}{$\begin{array}{l}\text { Personal psi experi- } \\
\text { ence? }\end{array}$} & Ganzfeld & .32 & .21 & -.40 & .69 & .06 \\
\hline & Waking RV & .20 & .14 & -.20 & .84 & .03 \\
\hline \multirow[t]{2}{*}{ Belief } & Ganzfeld & .25 & .26 & .03 & .97 & .01 \\
\hline & Waking RV & .16 & .18 & .08 & .94 & .01 \\
\hline \multirow[t]{2}{*}{ FP personality type } & Ganzfeld & .10 & .32 & -.68 & .51 & .11 \\
\hline & Waking RV & -.05 & .25 & -.99 & .33 & .16 \\
\hline \multirow[t]{2}{*}{ Extraversion } & Ganzfeld & .29 & .18 & .39 & .70 & .06 \\
\hline & Waking RV & .20 & .16 & .11 & .91 & .02 \\
\hline \multirow[t]{2}{*}{ Creativity } & Ganzfeld & .22 & .28 & .23 & .82 & .04 \\
\hline & Waking RV & .06 & .23 & .56 & .58 & .09 \\
\hline
\end{tabular}

We were also interested to see whether individual differences in shifts in consciousness brought about by sensory habituation might have a bearing on the success of the session. Participants completed the $\mathrm{PCl}$ and subscale scores were correlated with z-scores from ganzfeld trial similarity ratings. These data are given in Table 3. Variables that were expected to correlate negatively with psi performance are shaded. We can see that 3 of the 12 sub-dimensions gave rise to significant associations; ${ }^{11}$ greater success was achieved by participants who reported greater absorption in their subjective experience (AB), who reported lower arousal (AR), and who experienced less internal dialogue (ID). Associations with other sub-dimensions are small and do not approach significance.

11 Given the exploratory nature of these analyses and the intention to conduct confirmatory experiments, no correction was made for multiple analyses. 
Table 3.

Correlations between ganzfeld trial outcome and participants' ratings for the $\mathrm{PCl}$

\section{PCI Dimension}

\begin{tabular}{|c|c|c|c|c|c|c|c|c|c|c|c|c|}
\hline & $\mathrm{BI}$ & TS & DR & $A B$ & IA & IV & SA & AS & AR & RA & VC & ID \\
\hline$r$ & .01 & .17 & .10 & .34 & -.09 & .10 & -.20 & .03 & -.34 & -.06 & .03 & -.42 \\
\hline$p$ & .94 & .31 & .56 & .04 & .58 & .54 & .24 & .84 & .04 & .72 & .85 & .01 \\
\hline
\end{tabular}

Note: Body Image (BI), Time Sense (TS),Direction of Attention (DR),Absorption (AB), Imagery Amount (IA), Imagery Vividness (IV), Self-Awareness (SA), Altered State of Awareness (AS), Arousal (AR), Rationality (RA), Volitional Control (VC) and Internal Dialogue (ID)

\section{Discussion: Experiment 1}

For the ganzfeld condition participants achieved an overall sum-of-ranks profile that was significant, confirming our earlier finding (Roe \& Flint, 2007); however, performance in the waking-state remote viewing condition gave a sum-of-ranks profile that was not (quite) significant. While this might be interpreted as supporting the claim that ganzfeld stimulation does facilitate performance among novices, the difference between the two conditions is not significant (post hoc paired t-test on z-scores of similarity ratings gives $t[39]=.45, p=.657,2$-tail), and further work is needed to elucidate whether ganzfeld stimulation does, in fact, enhance performance in tasks such as this.

We administered Pekala's (1991) PCl to see if one might distinguish between responders and non-responders and gauge whether this had an effect on their success at the remote viewing task. Although not offering wholehearted support for the notion that a shift in consciousness is psi conducive, 3 of the 12 sub-dimensions of the $\mathrm{PCl}$ were significantly related to task success in a manner consistent with previous literature. The $\mathrm{PCl}$ dimension of arousal measures degree of muscular tension (Pekala, 1991, p. 132), and decreased tension was associated here with better performance, consistent with Braud and Braud's (1973) characterization of the psi-conducive features of the ganzfeld technique. The $\mathrm{PCl}$ dimension of absorption was positively related to ganzfeld outcome, supporting earlier work suggesting that absorption is associated with ESP (Roe, 2009; Marcusson-Clavertz \& Cardeña, 2011, report on the related constructs of hypnotizability and dissociation). Third, participants reporting lower levels of internal dialogue performed better, reminiscent of Carpenter's (2001) finding that reduced intellectualization was indicative of success in a ganzfeld ESP task. We determined, then, to see whether these patterns could be replicated in a second experiment.

Additionally, we intended to build on efforts to construct a model comprising psychological predictors of ESP performance. Since relatively little material from the remote viewing literature bears on this issue, we took our lead from ganzfeld and dream ESP research (Honorton, 1997; Roe et al., 2007) because it also incorporated free response ESP methods. Thus we concentrated on: practice of a mental discipline; personal psi experience; belief in the paranormal; FP personality type, extraversion; and self-reported creativity. However, none of these variables exhibited any association 
with performance in either the remote viewing or ganzfeld condition. In consequence, we decided that subsequent replications should focus on other measures that also have had some success in free response ESP testing: dissociative experiences, openness to experience, and transliminality. We therefore hypothesized:

$\mathrm{H}_{1}$ : Performance in the ganzfeld condition will be better than mean chance expectation (MCE) as measured by sum of ranks analysis of the independent judge's ranking of the target

$\mathrm{H}_{2}$ : Performance in the waking remote viewing condition will be better than mean chance expectation (MCE) as measured by sum of ranks analysis of the independent judge's ranking of the target

$\mathrm{H}_{3 a}$ : Scores on the transliminality scale will correlate positively with performance in the ganzfeld condition, as measured by z-scores of the independent judge's similarity ratings for the target site.

$\mathrm{H}_{3 \mathrm{~b}}$ : Scores on the transliminality scale will correlate positively with performance in the waking remote viewing condition, as measured by z-scores of the independent judge's similarity ratings for the target site.

$\mathrm{H}_{4 a}$ : Scores on the openness to experience scale will correlate positively with performance in the ganzfeld condition, as measured by z-scores of the independent judge's similarity ratings for the target site.

$\mathrm{H}_{4 \mathrm{~b}}$ : Scores on the openness to experience scale will correlate positively with performance in the waking remote viewing condition, as measured by z-scores of the independent judge's similarity ratings for the target site.

$\mathrm{H}_{5 a}$ : Scores on the dissociative experiences scale will correlate positively with performance in the ganzfeld condition, as measured by z-scores of the independent judge's similarity ratings for the target site.

$\mathrm{H}_{5 \mathrm{~b}}$ : Scores on the dissociative experiences scale will correlate positively with performance in the waking remote viewing condition, as measured by z-scores of the independent judge's similarity ratings for the target site.

$\mathrm{H}_{6}$ : Scores on dimensions of the Phenomenology of Consciousness Inventory will correlate with performance in the ganzfeld condition, as measured by z-scores of the independent judge's similarity ratings for the target site. 


\section{Method: Experiment $2^{12}$}

\section{Design}

The design was as for experiment 1, but with different individual differences measures as outlined above.

\section{Participants}

Two research assistants ( $\mathrm{AH}$ and $\mathrm{LK}$ ) were appointed to work on this project. A convenience sample of 40 volunteers (20F, 20M; mean age $=30.3$, range $=19-69$ years), consisting of friends, family, and other students, participated in this study. Participants were not selected on the basis of prior belief or experience. ${ }^{13}$

\section{Materials}

Materials were as for experiment 1 except that the PIF included measures of transliminality, openness to experience, and dissociation.

The Transliminality Scale: Form B (Thalbourne, 1998) is a 29-item measure using a T/F response format.

The Dissociative Experiences Scale (DES; Bernstein \& Putnam, 1986) is a 28-item self-report measure that assesses the frequency of dissociative experiences on a response scale that starts at $0 \%$ and increases by $10 \%$ increments up to $100 \%$. Responses across all items are averaged to obtain a mean DES score (range 0-100), with higher scores indicating greater tendency to dissociation.

Openness to Experience was measured using Goldberg's scale (IPIP: Goldberg et al., 2006), and has subscale alphas that range from .77 to .86 (Goldberg, 1999). It was chosen for use here because it is a public domain measure intended to represent the domain constructs of the NEO personality inventory (Buchanan, Johnson, \& Goldberg, 2005). Correlations between the IPIP and NEO scales for the openness to experience dimension range from .70 to .80 (Goldberg, 1999), suggesting that these instruments measure the same personality dimension.

\section{Procedure}

The procedure was as for experiment 1.

\section{Results: Experiment 2}

The ranks given to the target location on each of the 40 trials are given in Table 4 . The direct hit rate for the ganzfeld condition is $40 \%$, which is greater than mean chance expectation of $25 \%$ (binomial $p=.026$ ), whereas for the remote viewing condition it is exactly at chance level (binomial $p=.560$ ). Sum of ranks calculation confirms this pattern, with the ganzfeld condition scoring significantly better than chance $(z=2.47, p=.007)$; performance in the remote viewing condition approximated chance 
expectation ( $z=1.06, p=.145)$, as in experiment 1 . However, the $z$-scores for target ratings do not differ significantly between ganzfeld and waking RV conditions ( $t[39]=1.13, p=.265$ ).

Table 4.

Sum of ranks for target locations for ganzfeld and remote viewing trial

\begin{tabular}{|c|c|c|c|c|c|c|c|c|}
\hline & \multicolumn{4}{|c|}{ Rank } & Sum of & \multirow[t]{2}{*}{ z-score } & \multirow[t]{2}{*}{$p$ value } & \multirow[t]{2}{*}{ ES } \\
\hline & 1 & 2 & 3 & 4 & & & & \\
\hline Ganzfeld trials & $\begin{array}{c}16 \\
(40 \%)\end{array}$ & $\begin{array}{c}11 \\
(27.5 \%)\end{array}$ & $\begin{array}{c}8 \\
(20 \%)\end{array}$ & $\begin{array}{c}5 \\
(12.5 \%)\end{array}$ & 82 & 2.47 & .007 & .39 \\
\hline Waking trials & $\begin{array}{c}10 \\
(25 \%)\end{array}$ & $\begin{array}{c}12 \\
(30 \%)\end{array}$ & $\begin{array}{c}14 \\
(35 \%)\end{array}$ & $\begin{array}{c}4 \\
(10 \%)\end{array}$ & 92 & 1.06 & .145 & .17 \\
\hline
\end{tabular}

Z-scores were calculated as previously and were correlated against participants' scores on measures of transliminality, openness to experience, and dissociation. Results are given in Table $5 .{ }^{14}$ Positive correlations were hypothesized between personality dimensions and performance metrics. None of the associations approached significance.

Finally, we correlated $\mathrm{PCl}$ subscale scores against z-scores from ganzfeld trial similarity ratings as in experiment 1 (Table 6). The previous associations with absorption (AB), arousal (AR) and internal dialogue (ID) were not confirmed. The sole significant correlation (uncorrected for multiple analyses) was for time sense (TS).

Table 5.

Pearson correlations (and 2-tailed p values) between trial outcome and participants' scores on measures of Transliminality, Openness to Experience, and Dissociative experience

\begin{tabular}{lcc}
\hline & Ganzfeld trials & Waking RV trials \\
\hline Transliminality & $-.22(.18)$ & $-.11(.49)$ \\
Openness to experience & $.15(.35)$ & $.07(.66)$ \\
Dissociative experiences & $.21(.19)$ & $.04(.82)$ \\
\hline
\end{tabular}

14 Figures given here are different from those presented in earlier conference proceedings as a result of correcting scoring errors. 
Table 6.

Correlations between ganzfeld trial outcome and ratings for $\mathrm{PCl}$ dimensions

\begin{tabular}{ccccccccccccc}
\hline \multicolumn{10}{c}{} & \multicolumn{10}{c}{ PCI Dimension } \\
& $\mathrm{BI}$ & $\mathrm{TS}$ & $\mathrm{DR}$ & $\mathrm{AB}$ & $\mathrm{IA}$ & $\mathrm{IV}$ & $\mathrm{SA}$ & $\mathrm{AS}$ & $\mathrm{AR}$ & $\mathrm{RA}$ & $\mathrm{VC}$ & ID \\
\hline$r$ & .14 & .32 & .17 & -.02 & -.04 & .01 & .01 & .04 & .12 & .08 & .06 & .21 \\
$\mathrm{p}$ & .41 & .05 & .32 & .89 & .83 & .98 & .97 & .82 & .48 & .65 & .72 & .21 \\
\hline
\end{tabular}

\section{Discussion: Experiment 2}

Experiment 2 replicated our significant hitting in the ganzfeld condition whereas performance in the waking RV condition fell to chance levels. It is clear from conversations with participants during debrief that they found the RV activity difficult, leaving them feeling quite self conscious and out of their comfort zone, which may have acted to inhibit any psi component.

We incorporated measures of transliminality, openness to experience, and dissociation. However, these were not associated with z-scores for target ratings. Our initial analysis of these findings (Roe et al., 2012) did suggest moderate associations between openness to experience and waking RV performance, and for dissociation and ganzfeld performance, although the effects diminished when a calculation error was corrected during the preparation of this paper. These ostensible effects made psychological sense at the time, given that the awkwardness of the waking RV trial might lead those who value imaginistic and creative practices to be more comfortable with a task in which they are asked to cultivate psychic impressions while in a normal waking state, while the ganzfeld condition might be particularly suited to those who are predisposed to become deeply absorbed in their experience and might benefit most from participating in a ganzfeld study. On these grounds we considered it appropriate at the time to retain these measures in experiment 3.

Experiment 1 showed some promise in identifying $\mathrm{PCl}$ subscales that might relate to ganzfeld success, but the dimensions of arousal, absorption and internal dialogue were not confirmed here, although there was a significant positive association with time sense. This latter is reminiscent of Harley and Sargent's (1982) finding that successful participants gave significantly higher scores on a measure of state-shift than did those who were unsuccessful $(U=16.5, p<.05)$. Such distortions in time perception might be associated with general state-shifts that may be psi conducive (see Stanford, 1984, §6.3, for a discussion).

Thus a second replication was planned that would adopt the same design as experiment 2 and would test the same hypotheses. 


\section{Method: Experiment $3^{15}$}

\section{Design}

The design was as for experiment 2

\section{Participants}

One of the research assistants originally appointed to run this study withdrew before data collection began. As a consequence, the number of pre-planned sessions was reduced from 40 to 30 so that the workload was manageable for the remaining researcher (LH). A convenience sample of 30 volunteers (17F, 13M; Mean age: 26.9, range: 19-55 years), consisting of friends, family, and other students, participated in this study. All collected data are included in this report. Participants were not selected on the basis of prior belief or experience. ${ }^{16}$

\section{Materials}

Materials were as for experiment 2.

\section{Experiment 3 Results}

The ranks given to the actual target location on each of the 30 trials are presented in Table 7. In terms of first place ranks for targets, the direct hit rate for the ganzfeld condition is $43.5 \%$, which is again greater than chance expectation (binomial $p=.022$ ), whereas for the remote viewing condition it is $26.5 \%$ (binomial $p=.486$ ). By sum of ranks analysis, performance in the ganzfeld condition was significantly better than chance; performance in the remote viewing condition approximated chance expectation. ${ }^{17}$

Table 7.

Sum of ranks for target locations for ganzfeld and remote viewing trials

\begin{tabular}{|c|c|c|c|c|c|c|c|c|}
\hline & \multicolumn{4}{|c|}{ Rank } & \multirow[t]{2}{*}{ Sum of Ranks } & \multirow[t]{2}{*}{$z$-score } & \multirow[t]{2}{*}{$p$ value } & \multirow[t]{2}{*}{ ES } \\
\hline & 1 & 2 & 3 & 4 & & & & \\
\hline Ganzfeld trials & $\begin{array}{c}13 \\
(43.5 \%)\end{array}$ & $\begin{array}{c}9 \\
(30 \%)\end{array}$ & $\begin{array}{c}7 \\
(23.5 \%)\end{array}$ & $\begin{array}{c}1 \\
(3.5 \%)\end{array}$ & 56 & 3.02 & .001 & .55 \\
\hline Waking RV trials & $\begin{array}{c}8 \\
(26.5 \%)\end{array}$ & $\begin{array}{c}8 \\
(26.5 \%)\end{array}$ & $\begin{array}{c}7 \\
(23.5 \%)\end{array}$ & $\begin{array}{c}7 \\
(23.5 \%)\end{array}$ & 73 & 0.24 & .405 & .04 \\
\hline
\end{tabular}

15 An account of this study was given by Roe and Hickinbotham (2015).

16 We should like to thank Jacqui Wilson for her assistance as the independent judge.

17 We would like to thank an anonymous referee for suggesting that we compare these z-scores to see if they differ significantly. Dividing the difference by $\sqrt{ } 2$ (Rosenthal \& Rubin, 1979) gives Zdiff. $=1.97, p=.024$. However, when individual participant z-scores for target ratings for the ganzfeld and waking RV conditions are compared, they do not differ significantly between conditions $(t[29]=1.799, p=.082)$. 
Z-scores based on the independent judge's similarity ratings were used to look for covariation in performance across participants that might be associated with measures of transliminality, openness to experience, and dissociation, as in study 2. Results are given in Table 8. Again, none of these came close to significance.

We again explored associations between ganzfeld performance and scores on $\mathrm{PCl}$ subscales. These data are presented in Table 9. We can see that none of the 12 sub-dimensions gave rise to significant associations, and so earlier findings have not been confirmed.

Table 8.

Pearson correlations (and p values) between z-scores for independent judge's similarity ratings and participant scores on measures of Openness to Experience and Dissociative Experiences

\begin{tabular}{lcc}
\hline & Ganzfeld trials & Waking RV trials \\
\hline Transliminality & $-.13(.51)$ & $.15(.44)$ \\
Openness to experience & $.15(.45)$ & $.20(.30)$ \\
Dissociative experiences & $-.04(.84)$ & $-.05(.80)$ \\
\hline
\end{tabular}

Table 9.

Correlations between ganzfeld trial outcome and $\mathrm{PCl}$ ratings

\section{PCI Dimension}

\begin{tabular}{ccccccccccccc} 
& $\mathrm{BI}$ & $\mathrm{TS}$ & $\mathrm{DR}$ & $\mathrm{AB}$ & $\mathrm{IA}$ & $\mathrm{IV}$ & $\mathrm{SA}$ & $\mathrm{AS}$ & $\mathrm{AR}$ & $\mathrm{RA}$ & $\mathrm{VC}$ & ID \\
\hline$r$ & .06 & -.25 & -.04 & .04 & .12 & .01 & .02 & .01 & .25 & .02 & -.01 & -.02 \\
$p$ & .75 & .18 & .82 & .85 & .54 & .98 & .91 & .96 & .19 & .94 & .99 & .90 \\
\hline
\end{tabular}

\section{Summary and Discussion}

The primary aim of the present suite of experiments was to confirm and extend earlier findings by Roe and Flint (2007) that had suggested that novice participants could perform better than mean chance expectation at a remote viewing task when ganzfeld stimulation was used. In these replications, performance at a precognition task that used geographical locations as targets was compared under ganzfeld and waking RV conditions. The designs of these experiments were purposely kept constant so as to allow data to be combined and benefit from the increased statistical power associated with larger sample sizes without compromising the motivation of experimenters and participants, which can be a consequence of designing large studies. To test whether there were significant differences between the outcomes of the three experiments that would preclude their combination, a mixed ANOVA with 
experiment as between subjects IV and condition (ganzfeld versus waking RV) as within subjects IV was conducted. This confirmed that there were no differences between experiments in z-scores based on target ratings, $F(2,107)=.159, p=.853$. Combined data for target ranks across all three experiments are thus given in Table 10 .

We can see that the ganzfeld condition produced a cumulative hit rate of $39 \%$ (binomial $p=.0007$ ). A sum of ranks analysis - our preferred outcome measure - produced an overall z-score of 4.22, which is significant. Notably, participants in the ganzfeld condition performed significantly better than chance expectation in all three experiments, demonstrating a degree of replicability that is relatively unusual in parapsychology. We would encourage others to consider utilizing this method, which combines the advantages of ASC induction with a location-based feedback mode that participants find engaging, while avoiding problems of displacement that might occur with protocols in which participants are presented with a target and decoys during a judging phase. Of course, some of those features can also be found in the waking remote viewing condition, yet performance across a number of studies has been close to chance levels (cumulative hit rate $=27.5 \%$; binomial $p=.325$ ). However, the sum of ranks analysis did yield a $z$-score of 1.83 , which is significant.

Table 10.

Combined ranks for target locations for ganzfeld and remote viewing trials

\begin{tabular}{|c|c|c|c|c|c|c|c|c|}
\hline & \multicolumn{4}{|c|}{ Rank } & Sum of & \multirow[t]{2}{*}{$z$-score } & \multirow[t]{2}{*}{$p$ value } & \multirow[t]{2}{*}{ ES } \\
\hline & 1 & 2 & 3 & 4 & & & & \\
\hline Ganzfeld trials & $\begin{array}{c}43 \\
(39 \%)\end{array}$ & $\begin{array}{c}30 \\
(27.5 \%)\end{array}$ & $\begin{array}{c}26 \\
(23.5 \%)\end{array}$ & $\begin{array}{c}11 \\
(10 \%)\end{array}$ & 225 & 4.22 & .000012 & 0.40 \\
\hline $\begin{array}{l}\text { Waking RV } \\
\text { trials }\end{array}$ & $\begin{array}{c}30 \\
(27.5 \%)\end{array}$ & $\begin{array}{c}36 \\
(32.5 \%)\end{array}$ & $\begin{array}{c}25 \\
(22.5 \%)\end{array}$ & $\begin{array}{c}19 \\
(17.5 \%)\end{array}$ & 253 & 1.83 & .034 & 0.17 \\
\hline
\end{tabular}

It is noteworthy that the effect size for the ganzfeld condition across 110 trials $(0.40)$ is only a little higher than that for experienced SRI remote viewers and for experienced PRL ganzfeld participants (0.385 and 0.35 respectively - all comparison figures are taken from Baptista et al., 2015, p. 202), whereas the effect size for the waking state RV trial (0.17) is remarkably similar to figures reported for novice SRI viewers and novice PRL ganzfeld participants (0.164 and 0.17 ), which perhaps reflects the difficulty felt by some participants in acclimatizing to the protocol.

Additionally, there may be something particularly psi conducive about ASC intervention; indeed, Baptista et al. (2015) argue that despite the depiction of remote viewing as a waking state method, experienced viewers at SRI and SAIC did in practice employ methods intended to induce altered states of consciousness. The nature of such an advantage is unclear, however, given the failure of Pekala's (1991) 
Phenomenology of Consciousness Inventory to predict psi task success. When we combine data from all 110 participants (Table 11), we find that none of the dimensions relates to trial outcome. ${ }^{18}$

Table 11.

Correlations between ganzfeld trial outcome and ratings for $\mathrm{PCl}$ dimensions

\section{PCI Dimension}

\begin{tabular}{ccccccccccccc} 
& $\mathrm{BI}$ & $\mathrm{TS}$ & $\mathrm{DR}$ & $\mathrm{AB}$ & $\mathrm{IA}$ & $\mathrm{IV}$ & $\mathrm{SA}$ & $\mathrm{AS}$ & $\mathrm{AR}$ & $\mathrm{RA}$ & $\mathrm{VC}$ & $\mathrm{ID}$ \\
\hline $\mathrm{r}$ & .05 & -.08 & .10 & .11 & -.01 & .05 & -.03 & -.01 & -.02 & .04 & .06 & -.09 \\
$\mathrm{p}$ & .61 & .39 & .33 & .26 & .90 & .62 & .80 & .89 & .83 & .68 & .53 & .37 \\
\hline
\end{tabular}

A reviewer suggested that the repeated measures design adopted here could have led to asymmetrical order effects that would not be addressed simply by counterbalancing across trials. Indeed, given the very different nature of the two trials, it is plausible that exposure to one trial type could have had unexpected effects upon participants' openness to and comfort with the second trial type. To explore this, mean z-scores for the two conditions were calculated separately for trials in which it was completed first and second (see Table 12). It is clear that participants fared better within a condition type when it was presented second rather than first, suggesting a carry-over effect perhaps related to becoming acclimatized to the experiment or more comfortable with the experimenter, and that this improvement is independent of trial type (though it should be noted that the magnitude of improvement is small relative to the degree of variance within each cell). A 2x2 mixed ANOVA confirms this impression, giving a significant main effect for condition type, $F(1,47)=4.906, p=.032$, a nonsignificant order effect, $F(1,47)$ $=1.769, p=.190$, and nonsignificant interaction effect, $F(1,47)=.011, p=.918$. This could be seen as an argument for adopting repeated measures designs in which participants are given time to get used to the circumstances of the experiment.

Table 12.

Mean z-scores (and standard deviations) for target ratings by condition type and order of completion

\begin{tabular}{lcc} 
& Ganzfeld trials & Waking RV trials \\
\hline Completed first & $.26(.80)$ & $.01(.82)$ \\
Completed second & $.46(.76)$ & $.21(.90)$ \\
\hline
\end{tabular}

18 The value of bivariate correlations is, of course, dependent on the degree of variance in each of the variables. As one reviewer commented, it is possible that none of the participants experienced much alteration in their state of consciousness as a result of ganzfeld stimulation and this could have imposed a ceiling on the effect sizes of observed correlations against task performance. PCl responses were given on a 7-point scale. Each dimension score where ' 0 ' indicated an ordinary waking state and '7' indicated a major shift. Each dimension score was the sum of two items so that scores could range from 0 to 14 (some items are reverse scored). Summing across the three studies, average dimension scores ranged from 4.64 (volitional control) to 9.54 (direction of attention), with standard deviations from 2.47 (volitional control) to 5.11 (time sense), indicating that participants did experience some shift in their phenomenology of consciousness and that this varied across participants. 
Table 13 summarizes findings combined across experiments 2 and 3 that tested for associations between psi task performance and measures of transliminality, openness to experience, and dissociation. Effect sizes remain small and nonsignificant and do not give much encouragement that they might act as screening measures for identifying psi-conducive participants.

Table 13.

Correlations (and p values) for experiments 2 and 3 trial outcome and participants' scores on measures of Transliminality, Openness to Experience, and Dissociative experience

\begin{tabular}{lcc}
\hline & Ganzfeld trials & Waking RV trials \\
\hline Transliminality & $-.14(.25)$ & $.04(.72)$ \\
Openness to experience & $.15(.22)$ & $.14(.26)$ \\
Dissociative experiences & $.11(.38)$ & $.03(.84)$ \\
\hline
\end{tabular}

A number of commentators have speculated on which of the features of ganzfeld stimulation might be particularly psi conducive. For example, Honorton's (1977) influential noise reduction model required a sufficient level of cortical arousal to maintain conscious awareness, muscular relaxation (to reduce somatic noise), reduction of exteroceptive input from peripheral receptors, and deployment of attention toward internal mentation processes. In contrast, Braud and Braud (1973) argued that methods for facilitating ESP "are successful to the extent that they produce a shift toward the relaxation state" (p. 242), and showed that physical and mental relaxation alone can increase task success. These studies still included very low intensity white noise playing in the background, which could have encouraged attention to be focused internally, but performance was related to self-ratings and physiological measures of degree of relaxation per se, suggesting this was a primary factor. Schmeidler $(1994$, p. 116) adds that ASCs commonly enhance imagery and also encourage uncritical acceptance of whatever impressions come to mind, and elsewhere she emphasized their tendency to shift the percipient away from a reality-orientation and towards a suspension of disbelief (Schmeidler, 1988). These speculations fit reasonably well with mainstream characterizations of ASCs generally (e.g., Ludwig, 1966; Vaitl et al., 2005), and with the phenomenology of specific ASCs (cf. Cardeña, 2005; Sherwood, 2002; Wackermann et al., 2008). More provocatively, Stanford (1987) has questioned whether any of these elements is essential to the action of ESP, suggesting that success might have more to do with lab atmosphere, social interaction and excitement/expectancy rather than ASC induction itself, so that we might not expect any consistency with scales that measure such shifts. However, it is unclear how this account would explain the relatively poor performance of participants in the waking RV condition, which shares many of these properties.

Induction methods used in parapsychology can be quite unusual and involved, and might even be effective only in so far as they constitute an elaborate ritual, such that none of the elements plays an active role in facilitating ESP but when combined together they impress upon the participant the belief that ESP can occur in this situation in a self-fulfilling manner akin to a placebo effect. So long as these 
aspects are constantly incorporated together it is not possible to determine which of the component parts might be effective and which not.

This can be readily achieved in experiments that contrast conditions with and without certain of these elements while holding all other features constant. But although there have been some notable attempts to do just this (e.g., Braud et al., 1975; Rock et al., 2012), this kind of analytical approach focusing on the ASC itself has rather fallen out of favor (see Alvarado, 1998, for criticism of this). A return to a more critical analysis of the relation between ASCs and psi is certainly needed, in combination with a more systematic attempt to show that participants are consistently and reliably entering those supposed ASCs in the first place, for example using analysis of phenomenology in the tradition of Carpenter (2001), or using direct EEG measures. Techniques for achieving the latter have become much less invasive, and so are less susceptible to criticism around failing to reproduce the authentic ganzfeld experience (Parker, 2005).

\section{References}

Alvarado, C.S. (1998). ESP and altered states of consciousness: An overview of conceptual and research trends. Journal of Parapsychology, 62, 27-63.

Baptista, J., Derakhshani, M., \& Tressoldi, P. (2015). Explicit anomalous cognition. In E. Cardeña, J. Palmer, \& D. Marcusson-Clavertz (Eds.). Parapsychology: A handbook for the $21^{\text {st }}$ century (pp. 192-214). McFarland.

Bernstein, E. M., \& Putnam, F. W. (1986). Development, reliability and validity of a dissociation scale. Journal of Nervous and Mental Diseases, 74, 727-735. https://doi.org/10.1097/00005053-198612000-00004

Boyle, G.J. (1995). Myers-Briggs Type Indicator (MBTI): Some psychometric limitations. Australian Psychologist, 30, 71-74. https://doi.org/10.1111/j.1742-9544.1995.tb01750.x

Braud, W.G. (1978). Psi-conducive conditions: Explorations and interpretations. In B. Shapin \& L. Coly (Eds.) Psi and states of awareness: Proceedings of the $26^{\text {th }}$ annual conference of the Parapsychology Foundation (pp. 1-41). Parapsychology Foundation.

Braud, W. G., \& Braud, L. W. (1973). Preliminary explorations of psi-conducive states: Progressive muscular relaxation. Journal of the American Society for Psychical Research, 67, 6-46.

Braud, W.G., Wood, R., \& Braud, L.W. (1975). Free response GESP performance during an experimental hypnagogic state induced by visual and acoustic ganzfeld techniques: A replication and extension. Journal of the American Society for Psychical Research, 71, 409-427.

Cardeña, E. (2005). The phenomenology of deep hypnosis: Quiescent and physically active. Journal of Clinical and Experimental Hypnosis, 53, 37-59. https://doi.org/10.1080/00207140490914234

Cardeña, E., \& Marcusson-Clavertz, D. (2015). States, traits, cognitive variables, and psi, In E. Cardeña, J. Palmer, \& D. Marcusson-Clavertz (Eds.). Parapsychology: A handbook for the $21^{\text {st }}$ century (pp. 110-124). McFarland.

Carpenter, J. (2001). A psychological analysis of ganzfeld protocols. Proceedings of presented papers: Parapsychological Association 44 $4^{\text {th }}$ annual convention. (pp. 38-55)

Dalton, K. (1997). Exploring the links: Creativity and psi in the ganzfeld. Proceedings of presented papers: Parapsychological Association 40 th annual convention. (pp. 119-134)

Goldberg, L.R. (1999). A broad-bandwidth, public domain, personality inventory measuring the lower facets of several five-factor models. In I. Mervielde, I. Deary, F. De Fruyt, \& F. Ostendorf (Eds.), Personality psychology in Europe (Vol. 7) (pp. 7-28). Tilburg University Press. https://doi.org/10.1016/j.jrp.2005.08.007 
Goldberg, L.R., Johnson, J.A., Eber, H.W., Hogan, R., Ashton, M.C., Cloninger, C. R., \& Gough, H.G. (2006). The international personality item pool and the future of public domain personality measures. Journal of Research in Personality, 40, 84-96.

Hansel, C.E.M. (1989). The search for psychic power: ESP \& parapsychology revisited. Prometheus Books.

Harley, T.A., \& Sargent, C.L. (1980). Trait and state factors influencing ESP performance in the ganzfeld. In W.G. Roll (Ed.) Research in parapsychology 1979 (pp. 126-127). Scarecrow.

Honorton, C. (1977). Psi and internal attention states. In B. B. Wolman (Ed.), Handbook of parapsychology (pp. 435-472). Van Nostrand Reinhold.

Honorton, C. (1997). The ganzfeld novice: Four predictors of initial ESP performance. Journal of Parapsychology, 61, 143-158.

Keirsey, D., \& Bates, M. (1978). Please understand me: Character and temperament types. Prometheus Nemesis Books.

Ludwig, A.M. (1966). Altered states of consciousness. Archives of General Psychiatry, 15, 225-234.

Marcusson-Clavertz, D., \& Cardeña, E. (2011). Hypnotizability, alterations in consciousness, and other variables as predictors of performance in a ganzfeld psi task. Journal of Parapsychology, 75, 235-259.

Marks, D., \& Kamman, R. (1980). The psychology of the psychic. Buffalo, NY: Prometheus books.

Palmer, J. (1986). Statistical methods in ESP research. In H.L. Edge, R.L. Morris, J. Palmer, \& J.H. Rush (Eds.), Foundations of parapsychology: Exploring the boundaries of human capability (pp. 138-160). Routledge \& Kegan Paul.

Parker, A. (1975). States of mind: ESP and altered states of consciousness. Malaby.

Parker, A. (2005). Psi and altered states of consciousness. In M.A. Thalbourne \& L. Storm (Eds.) Parapsychology in the twenty-first century: Essays on the future of psychical research (pp. 65-89). Jefferson, NC: McFarland.

Pekala, R.J. (1991). Quantifying consciousness: An empirical approach. New York: Plenum Press. https://doi. org/10.1007/978-1-4899-0629-8

Pittenger, D.J. (2005). Cautionary comments regarding the Myers-Briggs Type Indicator. Consulting Psychology Journal Practice and Research, 57, 210 -221. DOI: 10.1037/1065-9293.57.3.210

Rock, A. J., Storm, L., Harris, K., \& Friedman, H. (2012). Shamanic-like journeying and psi-signal detection: I. In search of the psi-conducive components of a novel experimental protocol. Journal of Parapsychology, 76, 321-347.

Roe, C. A. (2009). The role of altered states of consciousness in extrasensory experiences. In M. Smith (Ed.), Developing perspectives on anomalous experience (pp. 25-49). McFarland.

Roe, C. A., Cooper, C. E., \& Martin, H. (2010). A comparison of ESP performance under remote viewing and Ganzfeld conditions. Abstracts of Presented Papers: The 53 ${ }^{\text {rd }}$ Parapsychological Association Annual Convention, (pp.21-22)

Roe, C. A., \& Flint, S., (2007). A remote viewing pilot study using a ganzfeld induction procedure. Journal of the Society for Psychical Research, 71, 230-234.

Roe, C. A., \& Hickinbotham, L. (2015). Performance at a precognitive Remote viewing task, with and without ganzfeld stimulation. Abstracts of presented papers: Parapsychological Association $58^{\text {th }}$ Annual Convention \& 39th SPR International Conference, University of Greenwich, London, July 16-19, 2015. (pp. 31-32)

Roe, C. A., Hodrien, A., \& Kirkwood, L. (2012). Comparing remote viewing and ganzfeld conditions in a precognition task. Abstracts of presented papers: Parapsychological Association 55 th Annual Convention, Durham, North Carolina, August 9-12, 2012. (pp. 36-38)

Roe, C. A., Jones, L., \& Maddern C. (2007). A preliminary test of the "four factor model" using a dream ESP protocol. Journal of the Society for Psychical Research, 71, 35-42. 
Schlitz, M., \& Gruber, E. (1980). Transcontinental remote viewing. Journal of Parapsychology, 44, 305-317. Schlitz, M., \& Gruber, E. (1981). Transcontinental remote viewing: A rejudging. Journal of Parapsychology, 45, 233-237.

Schlitz, M., \& Haight, J. (1984). Remote viewing revisited: An intrasubject replication. Journal of Parapsychology, 48, 39-49.

Schmeidler, G. R. (1994). ESP experiments 1978-1992: The glass is half full. In S. Krippner (Ed.) Advances in Parapsychological Research 7 (pp.104-197). McFarland.

Schwartz, S. (2015). Through time and space: The evidence for remote viewing. In D. Broderick \& B. Goertzel (Eds.), Evidence for psi: Thirteen empirical research reports (pp. 168-212). McFarland.

Sherwood, S. J. (2002). Relationship between the hypnagogic/hypnopompic states and reports of anomalous experiences. Journal of Parapsychology, 66, 127-150.

Stanford, R.G. (1984). Recent ganzfeld-ESP research: A survey and critical analysis. In S. Krippner (Ed.), Advances in parapsychological research 4 (pp. 83-111). McFarland.

Stanford, R.G. (1987). Ganzfeld and hypnotic-induction procedures in ESP research: Toward understanding their success. In S. Krippner (Ed.) Advances in parapsychological research 5 (pp. 39-76). McFarland.

Storm, L., Tressoldi, P. E., \& Di Risio, L. (2010). Meta-analysis of free-response studies, 1992-2008: Assessing the noise reduction model in parapsychology. Psychological Bulletin, 136, 471-485. https://doi. org/10.1037/a0019457

Subbotsky, E., \& Ryan, A. (2009). Motivation, belief and geomagnetic activity in a remote viewing task. Paper presented at the Society for Psychical Research 33 ${ }^{\text {rd }}$ International Conference, Nottingham University, 31 Aug-2 Sept.

Targ, R. (1994). Remote-viewing replication: Evaluated by concept analysis. Journal of Parapsychology, 58, 271-284.

Targ, R., \& Puthoff, H. (1974). Information transmission under conditions of sensory shielding. Nature, 252, 602-607. https://doi.org/10.1038/251602a0

Targ, R., \& Puthoff, H. E. (2005). Mind reach: Scientists look at psychic abilities. Charlottesville, VA: Hampton Roads.

Tart, C.T. (2007). Letter to the Editor. Journal of the Society for Psychical Research, 71, 193.

Tart, C.T., Puthoff, H.E., \& Targ, R. (1980). Information transmission in remote viewing experiments. Nature, 284, 191. https://doi.org/10.1038/284191a0

Thalbourne, M. A. (1998). Transliminality: Further correlates and a short measure. Journal of the American Society for Psychical Research, 92, 402-419.

Utts, J. (1996). An assessment of the evidence for psychic functioning. Journal of Scientific Exploration, 10, 3-30.

Utts, J., \& May, E. (2003). Non-sensory access to information: Remote viewing. In W. B. Jonas \& C. C. Crawford (Eds.), Healing, intention and energy medicine: Science, research methods and clinical implications (pp. 59-73). Churchill Livingstone. https://doi.org/10.1016/B978-0-443-07237-6.50011-5

Vaitl, D., Birbaumer, N., Gruzelier, J., et al. (2005). Psychobiology of altered states of consciousness. Psychological Bulletin, 13, 98-127. https://doi.org/10.1037/0033-2909.131.1.98

Wackermann, J., Pütz, P., Büchi, S., Strauch, I., \& Lehmann, D. (2002). Brain electrical activity and subjective experience during altered states of consciousness: Ganzfeld and hypnagogic states. International Journal of Psychophysiology, 46, 123-146. https://doi.org/10.1016/S0167-8760(02)00070-3Wackermann, J., Pütz, P., \& Allefeld, C. (2008). Ganzfeld-induced hallucinatory experience, its phenomenology and cerebral electrophysiology. Cortex, 44, 1364-78. https://doi.org/10.1016/j.cortex.2007.05.003 


\section{Appendix: List of targets used in the studies}

\section{Pool 1}

\begin{tabular}{|c|c|c|c|c|}
\hline Set & Site 1 & Site 2 & Site 3 & Site 4 \\
\hline 1 & $\begin{array}{c}\text { The Pentagon, Arlington, } \\
\text { Virginia }\end{array}$ & Easter Island & London Zoo, London, UK & $\begin{array}{l}\text { Uluru (Ayers' Rock), } \\
\text { Australia }\end{array}$ \\
\hline 2 & $\begin{array}{l}\text { Duomo Cathedral Flor- } \\
\text { ence, Italy }\end{array}$ & Mount Everest, Nepal & $\begin{array}{l}\text { Kirishi Oil Refinery, Sur- } \\
\text { gutneftegas, Russia }\end{array}$ & Alcatraz Island \\
\hline 3 & New York Central Station & Al-Kufrah aquifer, Libya & $\begin{array}{c}\text { Arusha National Park, } \\
\text { Tanzania }\end{array}$ & Niagara Falls \\
\hline 4 & Eiffel Tower & $\begin{array}{l}\text { Norfolk Naval Base, US } \\
\text { (ships docked to left) }\end{array}$ & Victoria Falls, Zimbabwe & $\begin{array}{c}\text { Eden Project, Cornwall, } \\
\text { UK }\end{array}$ \\
\hline 5 & $\begin{array}{c}\text { Bellecôte ski resort, } \\
\text { France }\end{array}$ & $\begin{array}{c}\text { Spaghetti junction, Bir- } \\
\text { mingham, UK }\end{array}$ & London Eye & St Peter's Basilica \\
\hline
\end{tabular}

\section{Pool 2}

\begin{tabular}{|c|c|c|c|c|}
\hline Set & Site 1 & Site 2 & Site 3 & Site 4 \\
\hline 1 & Palm Islands, Dubai & $\begin{array}{c}\text { Epsom Downs Race- } \\
\text { course }\end{array}$ & $\begin{array}{c}\text { Atomium Brussels, } \\
\text { Belgium }\end{array}$ & Piazza San Marco, Venice \\
\hline 2 & Lake Windermere, UK & Grand Canyon & $\begin{array}{l}\text { Three Mile Island Nucle- } \\
\text { ar plant }\end{array}$ & $\begin{array}{c}\text { Bahá'í House of Worship, } \\
\text { Delhi, India }\end{array}$ \\
\hline 3 & $\begin{array}{c}\text { Sequoia National Park, } \\
\text { California }\end{array}$ & $\begin{array}{l}\text { Edinburgh Castle, Scot- } \\
\text { land }\end{array}$ & $\begin{array}{l}\text { Cerro Verde copper } \\
\text { mine, Arequipa, Peru }\end{array}$ & $\begin{array}{c}\text { Bird's Nest Stadium, } \\
\text { Beijing, China }\end{array}$ \\
\hline 4 & Bondi Beach, NSW & $\begin{array}{c}\text { Estadio Nou Camp, } \\
\text { Barcelona }\end{array}$ & $\begin{array}{l}\text { Walshtown beg, } \\
\text { Ireland }\end{array}$ & Iguazu falls, Argentina \\
\hline 5 & Liberty Island & Giza pyramids & $\begin{array}{l}\text { Union Square, } \\
\text { Hong Kong }\end{array}$ & $\begin{array}{c}\text { Frankfurt Am Main Inter- } \\
\text { national Airport }\end{array}$ \\
\hline
\end{tabular}




\section{Performance à une Tâche de Remote Viewing Précognitif, avec et sans Stimulation Ganzfeld: Trois Expérimentations}

Résumé. Les recherches récentes conduites par le premier auteur ont cherché à incorporé la stimulation Ganzfeld au sein d'un protocole de remote viewing. Une expérimentation exploratoire initiale (Roe \& Flint, 2007) suggérait que des participants novices pouvaient décrire avec succès la localisation d'une cible sélectionnée aléatoirement au sein du dispositif Ganzfeld, sans marquer une comparaison directe avec la performance en état d'éveil. Cet article décrit une série de trois expérimentations subséquentes qui ont comparé la performance à une tâche de remote viewing dans une condition d'éveil avec une condition de stimulation Ganzfeld en utilisant un protocole de mesures répétées et contrebalancées. II n'y a que des variations mineures dans le protocole entre les trois expérimentations, afin d'assurer la combinaison des données dans l'analyse générale. Au total, 110 participants ont produit 43 succès dans la condition de stimulation Ganzfeld (39\%), donnant une déviation positive s'écartant significativement du hasard (somme des rangs $=225, p=.000012$ ), tandis que la condition de remote viewing éveillé a obtenu 30 succès (27.5\%), ce qui est marginalement meilleur que le résultat attendu par le hasard (somme des rangs $=253, p=.034$ ). La différence des scores $z$ pour le classement des cibles dans les deux conditions a approché du seuil significatif $(t[39]=1.86, p=.065)$. Dans l'expérimentation 1 , les mesures de différences inter-individuelles identifiées en tant que prédicteurs des performances psi n'étaient pas corrélées à l'évaluation des cibles. Les participants ont rempli l'Inventaire de phénoménologie de la conscience de Pekala (1991) afin de mesurer leur réactivité au protocole Ganzfeld et, parmi les douze sous-dimensions testées, les performances Ganzfeld étaient corrélées significativement avec une plus grande absorption dans leur expérience subjective, un éveil plus faible, et moins de dialogue interne. Dans les expérimentations 2 et 3, des mesures de transliminalité, d'ouverture à l'expérience et d'expériences dissociatives ont remplacé les précédentes mesures, sans obtenir davantage de corrélations aux succès dans la tâche. Les données de l'expérimentation 2 n'ont pas confirmé les découvertes utilisant le $\mathrm{PCl}$ de l'expérience 1, bien qu'une association significative fût trouvée avec la dimension du sens du temps. Dans l'expérimentation 3, aucune dimension du PCI ne fut corrélée avec la performance à la tâche, un pattern qui se confirma en combinant l'ensemble des données obtenues dans les trois expérimentations.

\section{Zur Leistung bei einer präkognitiven Fernwahrnehmungs-Aufgabe mit und ohne Ganzfeld-Stimulation: Drei Experimente}

Zusammenfassung. Der neue Forschungsansatz des Hauptautors hat versucht, die Ganzfeld-Stimulation als Teil eines Fernwahrnehmungsprotokolls zu integrieren. In einem ersten explorativen Experiment (Roe \& Flint, 2007) wurde vorgeschlagen, dass Neulinge erfolgreich einen zufällig ausgewählten Zielort im Ganzfeld-Kontext beschreiben können, aber es stellte keinen direkten Vergleich mit der Leistung im Wachzustand dar. In diesem Beitrag wird eine Reihe von drei aufeinander folgenden Experimenten beschrieben, die die Leistung bei einer Fernwahrnehmungsaufgabe im Wachzustand mit einer Ganzfeld-Stimulationsbedingung unter Verwendung eines ausbalancierten Designs mit Messwiederholun- 
gen vergleicht. Es wurden nur geringfügige Variationen im Design der drei Experimente vorgenommen, um eine Auswertung der Daten in einer zusammenfassenden Analyse zu ermöglichen. Insgesamt erzielten 110 Teilnehmer 43 Treffer in der Ganzfeld-Stimulationsbedingung (39\%), was eine hochsignifikante positive Abweichung von der Zufallserwartung darstellt (Rangsummen $=225, p=.000012$ ), während sie im Wachzustand 30 Treffer (27,5\%) erzielten, was geringfügig besser als die Zufallserwartung ist (Rangsummen $=253, p=.034$ ). Die Differenz der $z$-Scores für die Targeteinstufungen in den beiden Bedingungen näherte sich der Signifikanz $(t[39]=1,86, p=.065)$. In Experiment 1 waren die individuellen Unterschiede, die als Prädiktoren der Psi-Leistung identifiziert wurden, nicht mit den Targeteinstufungen verbunden. Die Teilnehmer füllten Pekalas (1991) Fragebogen zur Phänomenologie des Bewusstseins (PCl) aus, um ihre Reaktionsbereitschaft auf das Ganzfeld-Protokoll zu messen, und von den 12 getesteten Subdimensionen korrelierte die Ganzfeld-Leistung signifikant mit einer stärkeren Absorption in ihrer subjektiven Erfahrung, geringerer Erregung und geringerem innerem Dialog. In den Experimenten 2 und 3 wurden die individuellen Unterschiede durch Maße der Transliminalität, der Offenheit für Erfahrung und der dissoziativen Erfahrungen ersetzt, die jedoch in keinem Zusammenhang mit der Trefferleistung standen. Die Daten aus Experiment 2 bestätigten nicht die Ergebnisse aus Experiment 1 unter Verwendung des $\mathrm{PCl}$, obwohl ein signifikanter Zusammenhang mit der Dimension Zeitsinn gefunden wurde. In Experiment 3 korrelierten keine PCl-Dimensionen mit der Trefferleistung, ein Muster, das sich bei der Kombination der Daten aus allen drei Experimenten bestätigte.

\section{Rendimiente en una Tarea de Visión Remota Precognitiva con y sin Estimulación de Ganzfeld: Tres Experimentos}

Resumen. Investigaciones recientes del primer autor han tratado de incorporar la estimulación de ganzfeld como parte de un protocolo de visualización remota (remote viewing o RV). Un experimento exploratorio inicial (Roe y Flint, 2007) sugirió que los participantes novatos pueden describir con éxito la ubicación de destino seleccionada aleatoriamente en el contexto de ganzfeld, pero no se hizo una comparación directa con el rendimiento en un estado de vigilia. Este artículo describe una serie de tres experimentos posteriores que compararon el rendimiento en una tarea de visualización remota en una condición de vigilia con una condición de estimulación ganzfeld utilizando un diseño de medidas repetidas contrabalanceadas. Sólo hubo variaciones menores en el diseño en los tres experimentos para permitir combinar los datos en un análisis conjunto. En total, 110 participantes produjeron 43 aciertos en la condición de estimulación de ganzfeld (39\%), dando una desviación positiva muy significativa de la expectativa de azar (suma de rangos $=225, p=.000012$ ), mientras que en la condición de vigilia RV se obtuvieron 30 aciertos (27.5\%), marginalmente mejor que la expectativa de probabilidad (suma de rangos $=253, p=.034)$. La diferencia en las puntuaciones z comparando las dos condiciones casi fue significativa $(t[39]=1.86, p=.065)$. En el experimento 1 , las medidas de diferencia individual identificadas como predictores del rendimiento psi no se relacionaron con los aciertos. Los participantes completaron el Inventario de Fenomenología de la Consciencia (PCl) de Pekala (1991) para evaluar su capacidad de respuesta al protocolo de ganzfeld y a las 12 subdimensiones evaluadas, el rendimiento de ganzfeld correlacionó significativamente con una mayor absorción, menor excitación, y menor diálogo interno. En los experimentos 2 y 3, las medidas de diferencias individuales fueron reemplazadas por medidas de transliminalidad, apertura a la experiencia, y experiencias disociativas, pero no se correla- 
cionaron con los aciertos. Los datos del experimento 2 no confirmaron los resultados utilizando el PCI del experimento 1, aunque se encontró una asociación significativa con la dimensión del sentido del tiempo. En el experimento 3, ninguna dimensión del PCl correlacionó con el rendimiento de la tarea, un patrón que se confirmó cuando los datos de los experimentos se combinaron. 